\title{
Batman Şehit Şenay Aybüke Yalçın İl Halk Kütüphanesi
}

\author{
Batman Şehit Şenay Aybüke Yalçın Public Library
}

\section{Derya Alapala* ve Mehmet Emin Yılmaz ${ }^{* *}$}

$\ddot{O} z$

Bu çalışmada yeniden yapılandırılan Batman Il Halk Kütüphanesi ve bağll kütüphanelere ilişkin kapsamlı bilgi verilmektedir.

Anahtar Sözcükler: Batman Şehit Aybüke Yalçın Il Halk Kütüphanesi; halk kütüphaneleri; Batman; Türkiye.

\begin{abstract}
In this study, comprehensive information is given about the restructured Batman Provincial Public Library and its affiliated libraries.
\end{abstract}

Keywords: Batman Şehit Şenay Aybüke Yalçın Public Library; public libraries; Batman; Turkey.

\section{Giriş}

Kütüphanemiz 11 Temmuz 1984 tarihinde “Kültür Merkezi Kütüphanesi” adıyla Batman'1n ilk kültür merkezinde, Ziya Gökalp Mahallesi Yaşar Kemal Caddesi 6 numarada hizmete açılmıştır. 1987 yılına kadar Kültür Merkezi Kütüphanesi olarak hizmet veren kütüphanemiz, 1987 yılında Kültür Merkezi Müdürlüğü bünyesinden ayrılarak yine aynı binada müstakil "İlçe Halk Kütüphanesi Müdürlügü̈” adını almıştır. Batman'ın 16 Mayıs 1990 tarihinde il olmasıyla birlikte o tarihten itibaren de "İl Halk Kütüphanesi Müdürlüğü" olarak hizmet vermeye devam etmektedir. Kütüphanemiz 1984 yılından 2016 yılı kasım ayının ortalarına kadar Kültür ve Turizm Bakanlığı'na ait Eski Kültür Merkezi Binası'nın birinci ve ikinci katlarında hizmet vermekte iken, 2016 yılı kasım ayının ortasından, 2020 yılının kasım ayının ortasına kadar Kültür Merkezinin alt ve üst katlarında 1250 metrekarelik alanında geçici olarak hizmet vermiştir.

Mülkiyeti Batman Belediyesine ait 4 adet Bilgi Evi 5 Mart 2019 tarihli ve 3-127 sayılı Batman Belediye Meclis Kararı, 14 Mart 2019 tarihli ve 20-15 sayılı Batman Belediyesi Encümen kararı sonrasında 29 Mart 2019 tarihli protokol ve 1 Nisan 2019 tarihli Ek Protokol ile kütüphane olarak kullanılmak üzere 10 (on) yıllığına, mevcut belediye personeli ile birlikte geçici olarak Bakanlığımız tarafından yeterli personel kadro ihdası yapılıncaya kadar İl Halk Kütüphanesi Müdürlüğümüze tahsis edilmiştir. Bağlı şube kütüphaneleri; Petrolkent

\footnotetext{
* Batman Şehit Şenay Aybüke Yalçın İl Halk Kütüphanesi, Batman, Türkiye. E-posta: kutuphane72@ktb.gov.tr Batman Şehit Şenay Aybüke Yalçın Public Library, Batman, Turkey.E-mail: kutuphane72@ktb.gov.tr

** Batman Şehit Şenay Aybüke Yalçın İl Halk Kütüphanesi, Batman, Türkiye. E-posta: me-yilmaz@ hotmail.com Batman Şehit Şenay Aybüke Yalçın Public Library, Batman, Turkey.E-mail: me-yilmaz@hotmail.com
}

Geliş Tarihi - Received: 16.04 .2021

Kabul Tarihi - Accepted: 08.06.2021

Yayımlanma Tarihi - Published: 30.06 .2021 
mahallesinde Batman Petrolkent, Huzur mahallesinde Batman Ahmet Kaya, Gültepe mahallesinde Batman Yunus Emre şube halk kütüphaneleri ile Beşevler mahallesinde Batman Çocuk Kütüphanesi olarak 29 Mart 2019 tarihinden itibaren bakanlığımız bünyesinde hizmet vermektedir.

\section{Vizyon}

Yurttaşlarımızın bireysel ve yaşam boyu öğrenme çabalarını desteklemek, kütüphane kullanım alışkanlığını yaratmak, okuma kültürünü geliştirmek, kültürel mirasa, sanata ve bilime karşı duyarlılık oluşturmak, öncelikle Batman ve yöresinin sosyal, kültürel, ekonomik yönden kalkınması için gerekli olan bilgi ihtiyacını karşılamak, toplumun her yaş ve her kesimine bu yönde firsat eşitliği yaratarak, hızla gelişen bilgi çağına ayak uydurmaktır.

\section{Misyon}

Bilgi hizmetlerini çağdaş gelişmeler doğrultusunda düzenleyip, kullanıcılarının bilgi gereksinimlerini karşılamak, her yaş ve seviyedeki vatandaşlarımızın bilgi edinmek, kültür seviyelerini yükseltmek, zamanlarını değerlendirmek, istedikleri her konuda kitaplardan ve diğer bilgi kaynaklarından serbestçe ve ücretsiz olarak yararlanmalarını sağlamak, çağdaş bilgi hizmetlerini en üst düzeyde sağlayan evrensel çapta bir kütüphane olmaktır.

\section{Koleksiyon}

Koleksiyonumuz her konuda kitap, dergi (süreli yayınlar) ve kitap dışı materyallerden (ses kaseti, CD, video kaset, Braille kitap ve dergilerden) oluşmaktadır. Kitaplar, kütüphanemizin birinci ve ikinci katında çocuk ve yetişkinler okuma salonlarında açık raf sisteminde yerleştirilmiştir. Dergiler; son cilde ait son sayıları ile ciltli eski sayılar süreli yayınlar okuma salonunda alfabetik düzende yer almaktadır. Ciltsiz eski sayılar süreli yayın deposunda muhafaza edilmektedir. Kütüphanemize 2021 yılında Bakanlıkça abone olunan 259 adet dergi gelmektedir. Kütüphaneler ve Yayımlar Genel Müdürlüğü Yayın Seçme Kurulunca ilimiz halk kütüphanesi adına satın alınan, bağış ve resmi kurumlardan sağlanıp gönderilen yayınların miktarı yılda yaklaşık 5000 adet civarındadır. Kütüphanemizde Dewey Onlu Sınıflama Sistemi kullanılmaktadır.

\section{Bölümler}

\section{Zemin Kattaki Bölümler}

\section{Materyal Ödünç Verme Bölümü}

Yetişkin, çocuk ve engelli kütüphane kullanıcılarının birinci ve ikinci katlarda bulunan çocuk ve yetişkin okuma salonlardaki açık raf sistemiyle hizmet veren bu bölümde roman, hikâye, şiir ve deneme türü eserler ağırlıklı olmak üzere her konuda kitap yer almaktadır. Bu bölümdeki kaynaklar kütüphaneye üye olanlara 15 günlüğüne ödünç verilmektedir. Koleksiyonun çoğu güncel yayınlardan oluşmakta ve sürekli yeni yayınlarla zenginleştirilmektedir. Kütüphanelerimizden materyal ödünç alabilmek için üyelik zorunludur ve ücretsizdir. Kütüphane üyeliğine başvuru için T.C. Kimlik numarasını veya en az altı ay oturma izni almış yabancı kullanıcılar için yabancı kimlik numarasını gösterir belge yeterlidir. ${ }^{1}$ Kullanıcılar üye

\footnotetext{
${ }^{1} 15$ yaş üstü kütüphane kullanıcıları e-devlet platformu üzerinden kütüphaneye üye olabilmektedir.
} 
kartı veya kimlik numarasını gösterir belge ile ödünç alma işlemini gerçekleştirir. Üyelik her yıl güncellenmeli ve verilen üye kartları kaybedilmemelidir. Kütüphane kullanıcılarına bir seferde üç kitap/materyal ödünç verilir. Üyeliği olan her kullanıc1 15 gün süreyle istediği kitabı ${ }^{2}$ ödünç alabilmekte kitabı bitiremediği takdirde okuyucunun kütüphanemize müracaatı halinde uzatılmaktadır. Kullanıcılar, ödünç aldıkları materyale zarar vermeden zamanında iade etmek zorundadır. Zamanında iade edilmeyen materyaller için ilgiliye e-posta, SMS ve mektup ile hatırlatmada bulunularak, iade edilmesi istenir ya da telefon edilir. Üzerinde süresi dolmuş materyal bulunan kullanıcılara, üzerlerindeki materyalleri iade etmedikçe yeni materyal ödünç verilemez. İade edilmeyen, kullanılmayacak derecede yıpratılan ya da kaybedilen materyaller için kütüphane yönetimi tarafından, eserin piyasadan temin edilmesi, temin edilemiyorsa rayiç bedelini ödemesi istenir. Kitap bulunamadığ takdirde güncel bedeline cilt maliyeti de eklenerek okuyucudan tahsil edilir. Kitap bedelini ödemeyen ve bütün uyarılara rağmen kitabı iade etmeyen okuyucu hakkında Türk Ceza Kanunu'nun ilgili maddesine göre işlem yapılır.

\section{Engelsiz Ödünç Alma/ İade Cihazı}

Tüm kütüphane kullanıcıları engelsiz ödünç alma/iade cihazı üzerinden herhangi bir kişinin yardımına gerek duymadan yüksekliği engelli, çocuk ve yetişkinlere göre ayarlanabilen ekranı sayesinde otomatik olarak ödünç alma ve iade yapabilen cihazdır. Cihaz üzerinde işlem yaptıktan sonra ödünç alınan kitap/kitapların geri getirileceği tarihi gösteren fiş çıktısı alınabilmektedir. Kütüphaneden ödünç alınan kitap 15 gün sonra iade edildiğinde otomatik olarak kitap/kitaplar teslim alınmaktadır. Kitap teslim alındıktan sonra cihazın solunda bulunan materyal ödünç iade bankosuna teslim edilmektedir.

\section{Dışardan Kitap İade Makinası (Akıllı Kitap İade Sistemi)}

Kütüphane kullanıcıları resmi tatil ve mesai saatleri dışında kütüphane kapalı iken ödünç aldıkları kitabı hiç kimseye müracaat etmeden dışardan kitap iade sistemi sayesinde kendileri teslim edebilecekleri otomatik cihazdir.

\section{Kitap Temizleme Cihazı}

Kütüphanelerdeki kitaplar ortak kullanımda oldukları için binlerce kullanıcı tarafından dokunulmakta, raflarda okuyucuları beklerken toza maruz kalmakta, bulaşıcı hastalıkların taşıyıcısı olabilmektedir. Bu işlem, kitapların kitap temizleme makinasıyla dezenfekte edilmesi, tek tuşla her türlü bakterinin mor 1şınımla temizlenmesi, aromalı sterilizasyonla ${ }^{3}$ kitaplara zarar verilmeden yapılmaktadır.

\section{Halkla İlişkiler}

Kütüphaneyi kullanıcılarına sevdirme ve belli bir tutum benimsetmek üzere iletişim kurmak, olabilecek her türlü sorunları gidermek ve tanıtmak amacıyla kamu yararını esas alan düzenli

\footnotetext{
${ }^{2}$ Temel Başvuru Kaynakları; ansiklopediler, sözlükler, yıllıklar, atlaslar, bibliyografyalar, el kitapları, kılavuzlar, almanaklar, sıklıkla aranan materyaller ve dergilerin son sayıları dışarıya ödünç verilmez.

${ }^{3}$ Çam, limon veya lavanta kokulu saf aroma kullanarak 1 dakikada sterilizasyon yapılmaktadır.
} 
faaliyetlerimizin yürütüldüğü bölümdür. Bu kapsamda; danışmanlık, kurum hakkında bilgiler ve yayınlar, kamuoyu yaratma ve kullanıcılarımızla iletişim kurma faaliyetleri yapılmaktadır.

\section{Engelsiz Kütüphane}

Görme engelli ve az gören kullanıcılarımız için engelsiz kütüphane; 2.326 kitap dışı materyal, 11 adet internet bağlantılı bilgisayar, 1 adet kitap okuma makinası, 1 adet büyüteç sistemi ile engelli kullanıcılarımıza hizmet vermektedir. Kasetler CD çalar ile birlikte görme engelli kullanıcılarımıza ödünç verilmekte olup, koleksiyon kitap dışı materyal, Braille kitap ve dergilerden oluşmaktadır.

\section{Sergi Salonu}

Sanatsal ve kültürel eserlerin tanıtımının yapıldığı ve sergilendiği salonumuzdur.

\section{Müzik Atölyesi}

Kullanıcılarımıza yönelik çeşitli enstrümanların bulunduğu (piyano, gitar, keman, bağlama, kanun, ud, kabak kemane, erbane, darbuka) ödünç verildiği ve amatörce ve hobi seviyesinde müzik etkinliklerinin yapıldığı bölümdür.

\section{Çok Amaçlı Etkinlik Salonu}

Kütüphane kullanıcılarımıza ve personelimize yönelik çeşitli toplantı, kutlama, gösteri, eğitim ve kültürel etkinliklerin yapıldığı çok amaçlı salonumuzdur.

\section{Süreli Yayınlar Bölümü}

Süreli yayınların hizmete sunulduğu bölüm olup, dergilerin son cildine ait son sayıları ile ciltli eski sayılar süreli yayınlar okuma salonunda yer almaktadır. Ciltsiz eski sayılar ise kitap deposunda muhafaza edilmektedir. Kütüphanede Bakanlıkça abone olunan 250 derginin yanı sıra, Batman'da yayımlanan 24 adet yerel gazete hizmete sunulmaktadır.

\section{Olgunlar Bölümü}

Yaşı ilerlemiş kütüphane kullanıcılarımızın satranç ve dama gibi zeka oyunlarını oynayabileceği, dergi ve gazete okuyabileceği ve bilgi okuryazarlığı eğitiminin verildiği bölümümüzdür.

\section{Bilgi Edinme Bankosu}

Kütüphane kullanıcılarımızın kütüphanemiz ile ilgili iş/işlemler ve bölümlerle ilgili anlık sorularına yanıt veren ve yol gösteren birimimizdir.

\section{Emanet Eşya ve Vestiyer}

Kütüphane kullanıcılarımızın beraberinde getirdikleri poşet, çanta vb. eşyaların kilitli emanet dolaplarına bırakıldığı bölümdür. 


\section{Kafeterya ${ }^{4}$}

Kullanıcılarımızın ve kütüphane ziyaretçilerinin yeme içme ihtiyaçlarını giderebilecekleri bölümdür.

\section{Bekleme ve Dinlenme Salonu}

Kullanıcılarımızın ve kütüphanemizi ziyaret edenlerin bekleme ve dinlenme amaçlı kullandıkları bölümdür.

\section{Birinci Kattaki Bölümler}

\section{Çocuk Okuma Salonu}

Kullanıcılarımızın kendi kitaplarını kullandıkları veya okuma salonlarımızda bulunan ve açık raf sisteminde sergilenen kitaplardan yararlandığı bölümdür.

\section{Çocuk Bölümü}

3-16 yaş arası çocuk kullanıcılarımızın çeşitli yaş seviyesindeki zeka oyunları bölümü, çocuk cep sineması, masal anlatım bölümü, çocuk internet erişim merkezi, oyuncak bölümü ve bebek bölümünün bulunduğu salonlarımızdır.

\section{Oyun Bölümü}

3-16 yaş arası çocuk kullanıcılarımızın çeşitli zeka oyunlarının oynayabilecekleri salonumuzdur.

\section{Çocuk Cep Sineması}

3-16 yaş arası çocuk kullanıcılarımızın seviyelerine uygun film, animasyon film ve çizgi film gösterilerinin yapıldığı cep sinemasıdır.

\section{Masal Anlatım Bölümü}

Çocuk kullanıcılarımıza masal anlatıcı eşliğinde çeşitli masal ve hikâyelerin anlatıldığı bölümdür.

\section{Çocuk Internet Erişim Merkezi}

Çocuk kütüphane kullanıcılarımızın çocuk internet erişim merkezinde bulunan 24 adet bilgisayardan ücretsiz eğitim ve araştırma amaçlı faydalandığı bölümdür. Çocuk kütüphane kullanıcıları taşınabilir bellek (USB), CD ve DVD'ye veri aktarabilir, ancak kütüphane bilgisayarlarına program kuramaz ve kaldıramazlar. Ayrıca güvenli olmayan ve zararlı içerik barındıran (terör, pornografi, kumar vb.) sitelere giriş yapamazlar.

\section{Oyuncak Bölümü}

Çocuk kullanıcılarımızın çeşitli oyunlar veya oyuncaklarla oynadıkları bölümdür.

\footnotetext{
${ }^{4}$ Batman Belediyesi ve Kızılay Batman Şubesinin ortaklaşa yürüttüğ̈̈ “Çalışmak Sizden Çorba Bizden” projesi kapsamında kütüphane girişinde hafta içi her gün sabah saatlerinde okuyucularımıza sıcak çorba ikram edilmektedir.
} 


\section{Bebek Bölümü}

0-3 yaş arası bebeklerin kitap ve kütüphane ile olabildiğince erken yaşta buluşmalarını sağlamak amacıyla anne-baba veya bakıcıları eşliğinde kitap ve okuma sevgisini özendirerek kütüphane kullanımını erken yaşta alışkanlık haline getirmeyi amaçlayan çalışmaların yapıldığı bölümdür. Bu bölümde bir yandan da kaynakların bebeğe uygunluğu konusunda çocuk gelişim uzmanları tarafından hazırlanan bebek eğitim programlarıyla ailelerin bilinçlenmesine katkıda bulunmaya çalışılmaktadır.

\section{İkinci Kattaki Bölümler}

\section{Yetişkin Okuma Salonu}

Yetişkin kütüphane kullanıcılarımızın kendi kitapları veya okuma salonlarımızda bulunan ve açık raf sisteminde sergilenen kitaplardan yararlandığı bölümdür.

\section{Katalog Tarama Cihazı}

Kütüphanemize RFID Akıllı Kütüphane Sistemi kurulmuştur. Birinci kattaki çocuk okuma salonu ile ikinci kattaki yetişkin okuma salonunda kütüphane kitapları ve aranılan kitaplarla ilgili yer bilgisi katalog tarama cihazı üzerinden görsel olarak görülebilmekte ve fiş çıktısı alınabilmektedir.

\section{Batman Araştırmaları Merkezi}

Batman'a dair konuların incelendiği, araştırıldığı bölüm olup, ilgili bilgi ve belgelerin fiziki ve dijital ortamda araştırmacıların kullanımına sunulduğu yerel, ulusal ve uluslararası düzeyde araştırma yapılmasına olanak sağlayan merkezdir. Bu bölümde amaç ve kentsel araştırma konuları çerçevesinde uzmanlarca eğitim programları düzenlenmektedir. Koleksiyon, farklı disiplinlerden gelen bilgi kaynaklarının, kent kültürü ve tarihiyle ilgili dokümanlardan ${ }^{5}$ derlenmekte ve şehir araştırmacılarının hizmetine sunulmaktadır. Merkezde Batman hakkında yazılmış kitap ve dergiler ile Batmanlı yazar ve şairlerin kitaplarından oluşan "yerel koleksiyon" adı altında bulunmaktadır. Çeşitli kurum ve kuruluşlar ile şahısların elinde bulunan Batman kültürü ve tarihine ait nadir belge ve arşivlerden elde edilen dijital kopyalar hazırlanarak araştırmacıların hizmetine sunar.

\section{Bilim, Teknoloji ve Yapım Atölyeleri}

Bilim Atölyesi

Bilimsel eğitim alanlarında, ürüne yönelik araştırma geliştirme çalışmalarının İl Milli Eğitim Müdürlügü işbirliğgiyle yürütüldüğü teknolojik bölümdür.

\section{Teknoloji Atölyesi}

Ülke gelişimine yüksek katkı sağlayabilecek yetenekli öğrencilerin Batman genelinde tespit edilmesi ve bu öğrencilerin gelişimleri için gerekli desteklerin sağlanması için gençlerin takım çalışması, yenilikçi düşünce, proje geliştirme odaklı eğitim programları ile daha üretken olmalarının sağlanması amaçlanmakta olup, İl Milli Eğitim Müdürlüğü işbirliğinde yeterli fiziki

\footnotetext{
${ }^{5}$ Belgeler, haritalar, fotoğraflar, tezler, kartoğrafya, kentsel arşiv, yaşam ve şehir istatistikleri, kültürel ve sosyal araştırmalar-somut olmayan kültürel miras ürünleri ile folklor araştırmaları, kentsel dönüşüm ve yatırım araştırmalarına ait yayınlar.
} 
imkânlar ve donanımla gençlerin bilim ve teknolojide yenilik üretebilen ve diğer insanları da bu doğrultuda etkileyebilen bireyler olmaları hedeflenmektedir. Teknoloji atölyesinde hayatın her alanında yer alan robot, araba, telefon, bilgisayar, televizyon, banka kart1, mikrodalga vb. eşyaları deneyerek ve keşfederek mükemmel olmalarını sağlamak üzere robotik kodlama ve programlama dillerini uygulamaya geçiren eğitim programlarının yapılması tasarlanmaktadır.

\section{Yapım Atölyesi}

Çeşitli yaş gruplarındaki öğrencilerin hayal gücü ve yaratıcı düşüncelerinin yardımıyla İl Milli Eğitim Müdürlüğü işbirliğiyle görevlendirilecek öğretmenin rehberliğinde özgün ürünler ortaya çıkarılması amacıyla kullanılan öğrenme ortamıdır.

\section{Üçüncü Kattaki Bölümler}

\section{Teknik Hizmetler Bölümü}

Kitabın ve kitap dışı materyallerin kütüphaneye girişinden rafa çıkışına kadar olan tüm teknik hizmetlerin (kaşelenmesi, kataloglama ve sınıflandırılması, etiketlenmesi ve barkodlanması vb.) yapıldığı bölümdür.

\section{Kurs Odast}

Kullanıcılara bilgisayar, resim, tezhip, dama, zeka oyunları, çocuk gelişimi ve soru çözüm kursları verilmekte olup, kurslar Halk Eğitim Merkezi işbirliğiyle yapılmaktadır. ${ }^{6}$

\section{Ĕ̈itim Salonu}

Kullanıcıların ve personelin çeşitli konularda eğitim aldığı ve kütüphanenin tanıtımının periyodik aralıklarla yapıldığı, kullanıcı eğitimin bölümüdür.

\section{Yetişkin Cep Sinemast}

Yetişkin kullanıcılarımıza yönelik telif hakları satın alınmış ve bakanlıkça gönderilen filmlerin gösteriminin yapıldı̆̆ı cep sinemasıdır.

\section{Temel Başvuru Kaynakları Bölümü}

Ansiklopedi, sözlük, yıllık, elkitabı, rehber, almanak, bibliyografya vb. danışma kaynakları ile sık aranan kitaplar yer almaktadır. Amaç okuyucunun hızlı bir şekilde kısa ve öz bilgiye ulaşmasını sağlamak olup, bu bölümdeki kaynaklar kütüphane içi kullanım içindir.

\section{Yetişkin Internet Erişim Merkezi}

Yetişkin kullanıcılarımızın 50 adet bilgisayardan ücretsiz eğitim ve araştırma amaçlı faydalandığı bölümdür. Kullanıcılar taşınabilir bellek (USB), CD ve DVD'ye veri aktarabilir, ancak kütüphane bilgisayarlarına program kuramaz ve kaldıramazlar. Ayrıca güvenli olmayan ve zararlı içerik barındıran (terör, pornografi, kumar vb.) sitelere giriş yapamazlar.

\footnotetext{
${ }^{6}$ Kurslar, zekâ oyunları (çocuk bölümünde hafta içi her gün 13:00-16:00 saatleri arasında), dama (çocuk bölümünde hafta içi pazartesi, salı, çarşamba günleri saat 13:30-15:00 arasında), soru çözüm (Cuma günü hariç her gün 10:00-14:30 saatleri arasında kurs odasında), çocuk gelişimi (çocuk bölümünde hafta içi her gün çocuk eğitim ve aktivite kursu) olmak üzere düzenlenmektedir.
} 


\section{Gezici Kütüphane}

Gezici Kütüphane kapsamında daha önce belirlenen merkeze ve ilçelerimize bağlı belde ve köylerden ibaret 20 duraktan, üye olmak şartıla 15 günlüğüne evlere ödünç kitap verilmektedir. Gezici kütüphane kullanıcılarımız kısa sorulara cevap bulabilecekleri temel başvuru kaynaklarından araç içerisinde faydalanmaktadır. Pandemi sürecinde İl Milli Eğitim Müdürlüğü ile işbirliği yaparak EBA Noktası olarak da hizmet vermektedir. Ayrıca Batman Gençlik Merkezi ile işbirliği yapılarak gidilen duraklarda çeşitli geleneksel çocuk oyunlarının oynanması sağlanmaktadır. Gezici kütüphanemizin 2021 y1lı hizmet programı aşağıda tablo halinde verilmektedir.

\section{Tablo}

Batman Şehit Şenay Aybüke Yalçın Il Halk Kütüphanesi Gezici Kütüphane 2021 Programı

\begin{tabular}{c|c|c}
\hline \multicolumn{1}{c}{ Gün } & \multicolumn{1}{l}{ Saat } & Görev Yerleri \\
\hline PAZARTESİ & $09.00-15.30$ & BALPINAR BELDESİ \\
SALI & $09.00-15.30$ & İKİKÖPRÜ BELDESİ \\
ÇARŞAMBA & $09.00-15.30$ & BIÇAKÇI KÖYÜ \\
PERŞEMBE & $09.00-15.30$ & İİTEPE KÖYÜ \\
CUMA & $09.00-15.30$ & BİNATLI KÖYÜ \\
& Haftasonu Tatili & \\
PAZARTESİ & $09.00-15.30$ & ZORKÖY \\
SALI & $09.00-15.30$ & KOCALAR KÖYÜ \\
ÇARŞAMBA & $09.00-15.30$ & KAVAKLI KÖYÜ \\
PERŞEMBE & $09.00-15.30$ & AKOBA KÖYÜ \\
CUMA & $09.00-15.30$ & ÇEVRIMOVA KÖYÜ \\
\hline
\end{tabular}

Batman Şehit Şenay Aybüke Yalçın İl Halk Kütüphanesi sahip olduğu teknik altyapı ve koleksiyonu ile ülkemizin en gelişmiş kütüphane ve bilgi merkezi olma yolunda hizmetlerini zenginleştirmekte olup, çalışma saatleri pandemi nedeniyle 02.03.2021 tarihi itibariyle 08.0017.00 olarak belirlenmiștir.

\section{İlçe Halk Kütüphaneleri}

\section{Beşiri İlçe Halk Kütüphanesi Müdürlü̆̆̈̈}

Kütüphane 27.04.1987 tarihinden bu yana Mülkiyeti Bakanlığımıza ait $280 \mathrm{~m}^{2}$ 'lik tek katlı bir binada hizmet vermektedir. Mevcut bina eski Halk Eğitimi Merkezi Müdürlüğü binası olması nedeniyle Kütüphane olarak planlanmadığından koleksiyonun zenginleştirilmesine ve giderek hızla artan kullanıcıya hizmet vermekte yetersiz kalmaktadır.

\section{Gercüş İlçe Halk Kütüphanesi}

Kütüphane ilk defa belediye hizmet binasında 02.02.1994 tarihinde açılmıştır. 1996 yılında Gercüş Lisesine taşınmıştır. 1996-2000 yılları arasında lise binasında hizmet etmeye devam 
eden kütüphane 18.05.2000 tarihinden itibaren Bakanlığımızca yatırım yoluyla yaptırılan Bodrum +3 katlı bir binada $1.200 \mathrm{~m}^{2}$ alanda hizmet vermektedir.

\section{Hasankeyf İlçe Halk Kütüphanesi}

Kütüphane ilk defa 22.11.1995 tarihinde TRT Diyarbakır Radyosu 10. Saat Programı aracılığıyla Hasankeyf Belediyesine ait bir hal dükkânında "Hasankeyf 10.Saat Programı Kütüphanesi" adıyla hizmete açılmıştır. 2008 yılında Bakanlığımıza bağlanarak "Hasankeyf İlçe Halk Kütüphanesi” adını almıştır. Hasankeyf İlçe Halk Kütüphanesi 17.03.2015 tarihinde Bakanlığımızca onarımı ve tefrişi yapılan Belediyeye ait eski Kaymakamlık binasına taşınmıştır. TOKİ tarafından yaptırılan mevcut binasına ise 27.11.2017 tarihinde taşınmıştır. Bodrum, zemin ve +1 kattan ibaret olan kütüphane binamızın toplam kullanım alanı 1.311 metrekare olup, yetişkinler ve çocuklar için ayrı okuma salonları, 20 bilgisayardan oluşan internet erişim merkezleri, ödünç kitap verme salonları ile süreli yayınlar ve danışma kaynakları bölümü bulunmaktadır. Kütüphanede 2019 yılı sonu itibarıyla her konuda yaklaşık 12.000 kitap, 40 çeşit dergi bulunmaktadır. İlçemize göre oldukça büyük, yeni ve modern tarzda yaptırılan kütüphane binası mimarisi Artuklu mimarisi tarzındaki Zeynel Bey Türbesi'nden esinlenilmiştir. Donanımı, koleksiyonuna eklenen kaynaklardaki çeşitliliği ile Türkiye'de ilçe halk kütüphaneleri arasında örnek olan kütüphane, uzunca bir süre artacak nüfus yoğunluğunun da kültürel ihtiyacını karşılayabilecek kapasiteye sahiptir.

\section{Kozluk İlçe Halk Kütüphanesi}

19.11.1999 tarihinde Kozluk Belediyesine ait binada "Kozluk İlçe Halk Kütüphanesi" adıyla açılmıştır. 1999 yılından 2010 yılına kadar önceden belediye ait olan SGK İş Hanında hizmet vermiştir. 18.10.2010 tarihinde Milli Eğitim Bakanlığı Halk Eğitim Merkezinin 1.katında 25 $\mathrm{m}^{2}$ 'lik bir salona taşınmıştır. 01.04.2016 tarihinden itibaren Kozluk Vakıf Müdürlüğü mülkiyetli 2 katlı $405 \mathrm{~m}^{2}$ 'lik alanda 130 kişilik oturma kapasitesiyle prefabrik binada kütüphane hizmeti verilmektedir.

\section{Sason İlçe Halk Kütüphanesi}

Kaymakamlıkça hazırlanan SODES Projesi kapsamında; çarşı merkezinde eski iki katlı bir binanın onarılarak, kütüphane olarak düzenlenmesiyle 2010 yılında hizmete açılmıştır. Proje süresinin bitimini takiben kütüphane Bakanlığımıza devredilmiştir. Kütüphane Sason İlçe Halk Eğitimi Merkezi Müdürlüğü binasının giriş katında 05.04.2016 tarihinden itibaren 317 m2'lik alanda hizmet vermektedir. 


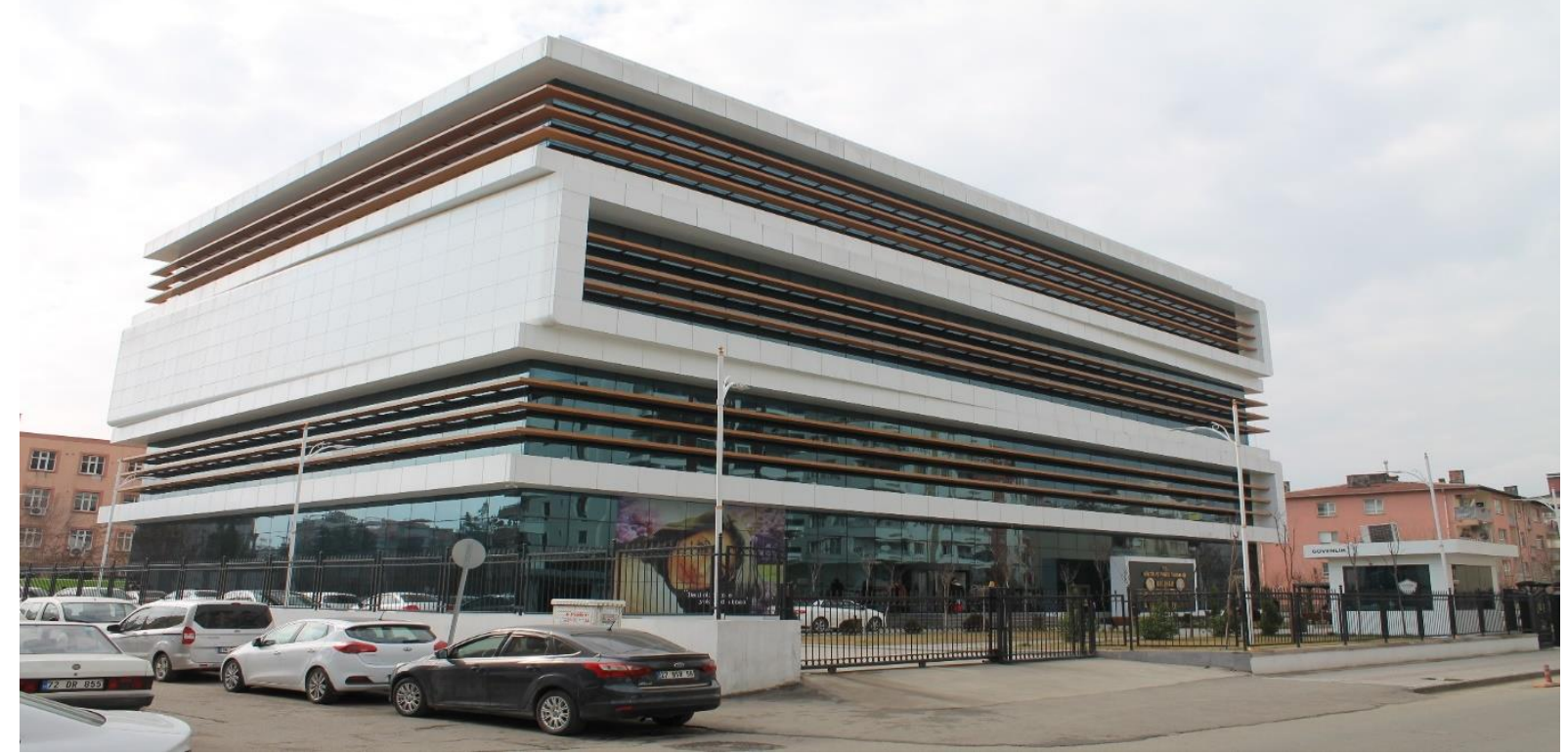

Görsel 1. Batman Şehit Şenay Aybüke Yalçın İl Halk Kütüphanesi’nin dış cephe görünüşü

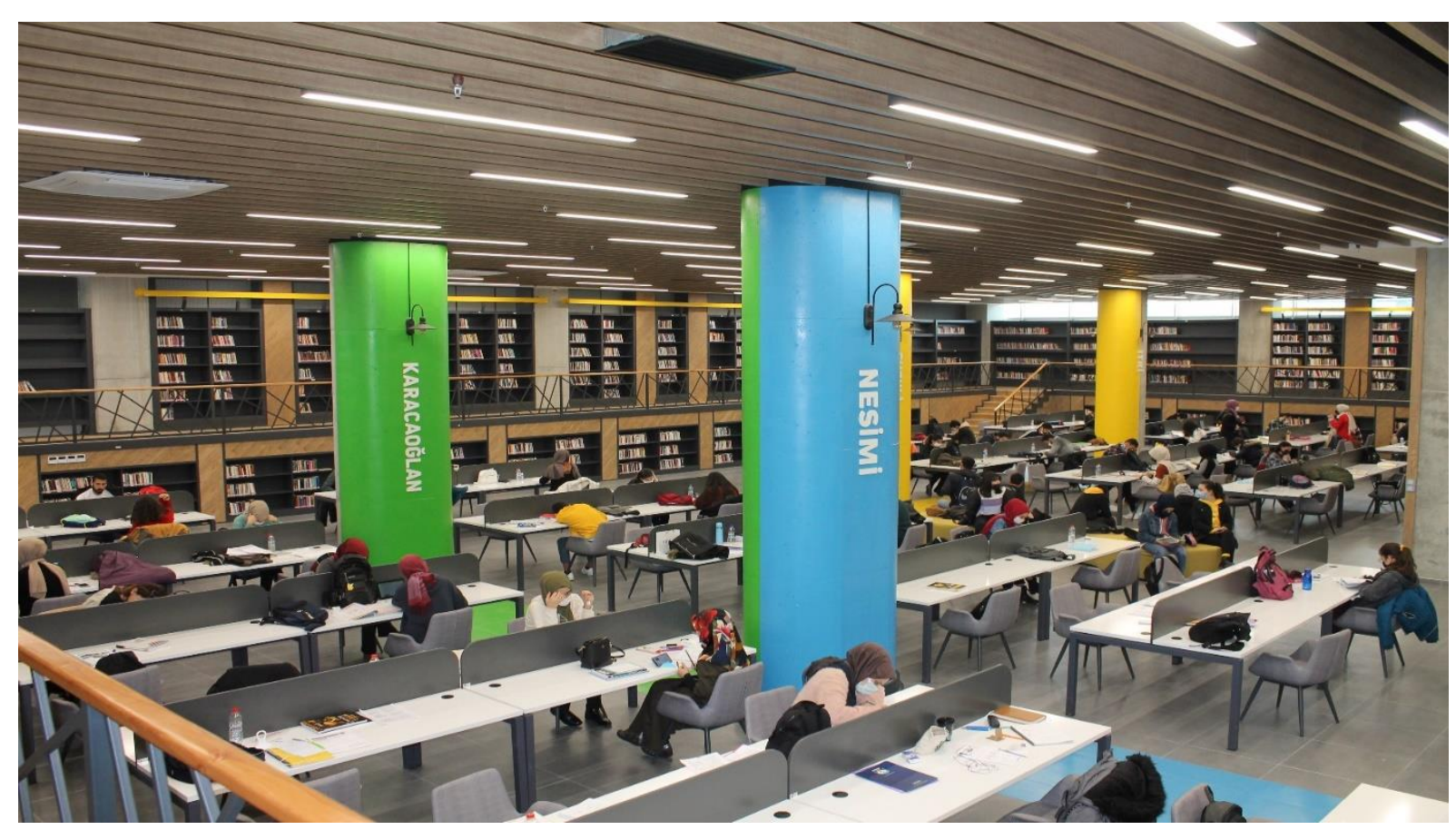

Görsel 2. Yetişkin okuma salonu 